William M. Splinter MD FRCPC, Helen B. MacNeill MD FRCPC,

Eugene A. Menard MD FRCPC, Elliot J. Rhine MD FRCPC, David J. Roberts MD FRCPC, Marion H. Gould MD FRCPC

\title{
Midazolam reduces vomiting after tonsillectomy in children
}

The purpose of this study was to assess the effect of midazolam on vomiting after tonsillectomy in children. We compared 215 children aged 1.5-14 yr undergoing tonsillectomy or adenotonsillectomy under general anaesthesia with nitrous oxide and halothane. In a double-blind fashion the subjects were administered either placebo or midazolam $75 \mu \mathrm{g} \cdot \mathrm{kg}^{-1}$ iv after induction of anaesthesia. After the operation, the number of emetic episodes and the length of stay in hospital were recorded. The groups were similar with respect to age, weight, sex, mode of induction, duration of anaesthesia, surgical procedure, opioid administration and length of stay in the PAR and the Day Care Surgical Unit. The 108 midazolam-treated children had a lower incidence ( $42 \%$ vs $57 \%$ ) of vomiting than the placebo group, $P<0.02$. The placebo group had a higher incidence ( $9 \%$ vs 2\%) of unscheduled admissions to hospital due to nausea and vomiting, $P<0.05$. It is concluded that midazolam administered intravenously to children intraoperatively reduces vomiting after tonsillectomy.

Cette étude vise à évaluer chez les enfants l'effet du midazolam sur les vomissements post-amygdalectomie. Nous étudions 215 enfants dont l'áge se situe entre 1,5 et 14 ans soumis à une amygdalectomie ou d̀ une adéno-amygdalectomie sous anesthésie générale à l'halothane et au protoxyde d'azote. Les sujets reçoivent en double aveugle soit un placebo soit du midazolam $75 \mu \mathrm{g} \cdot \mathrm{kg}^{-1}$ après l'induction de l'anesthésie. Après l'intervention, le nombre d'épisodes émétiques et la durée du séjour à

\section{Key words}

ANAESTHESIA: complications;

SURGERY: tonsillectomy, adenoidectomy;

vOMITING: postoperative, antiemetics, midazolam.

From the Department of Anaesthesia, University of Ottawa and Children's Hospital of Eastem Ontario, Ottawa, Ontario, Canada K1H 8Ll.

Address correspondence to: Dr. William Splinter,

Department of Anaesthesia, Children's Hospital of Eastern

Ontario, 401 Smyth Rd., Ottawa, Ontario, Canada, K1H 8L1.

Presented in part at the 49th Annual Meeting of the

Canadian Anaesthetist's Society, Toronto, June 1992.

Accepted for publication 4th November, 1994. l'hôpital sont enregistrés. Les groupes sont comparables pour l'âge, le poids, le sexe, le mode d'induction, la durée de l'anesthésie, lintervention chirurgicale, l'administration de morphinique et la durée du séjour en salle d'opération et à l'unité de chirurgie d'un jour. Les 108 enfants traités au midazolam vomissent moins (42\% vs 57\%) que le groupe placebo. Lincidence des admissions imprévues à l'hôpital pour nausées est vomissements est plus élevée dans le groupe placebo $19 \%$ vs $2 \%, P<0,05$ ). Nous concluons que l'administration iv de midazolam pendant l'intervention diminue lincidence des nausées et des vomissements après l'amygdalectomie.

Vomiting is an important, common and unpleasant sequel of paediatric general anaesthesia. Twenty per cent of children aged one to five years and $33 \%$ ages $>$ six years vomit ${ }^{1}$ after general anaesthesia. The reported incidence of vomiting after tonsillectomy in children is as high as $75 \%{ }^{2}$ Persistent vomiting may result in expensive delays in discharge from hospital and unscheduled admissions and readmissions. ${ }^{3,4}$ More important, prolonged postoperative vomiting (POV) may cause dehydration, metabolic derangements, seizures and if mismanaged, death. ${ }^{5,6}$

The aetiology of postoperative vomiting is multifactorial. A variety of means has been employed to prevent and treat this problem. Established antiemetic drugs, such as droperidol have been shown to be effective. ' Benzodiazepines, such as diazepam, lorazepam and midazolam, are usually administered for their anxiolytic, amnestic and sedative effects. Recently, the administration of these drugs has been associated with a decrease in nausea and vomiting among oncology patients who have received chemotherapeutic agents. ${ }^{8-10}$ Khalil et al. ${ }^{11}$ studied the effect of lorazepam $i v$ on POV after ophthalmic surgery in children. They observed a decrease in POV in patients treated with lorazepam. This research has lead one to question whether other benzodiazepines may diminish POV. Recently, we observed that midazolam has antiemetic effects which are similar to droperidol among children undergoing strabismus surgery. ${ }^{3}$ There have not been any studies of the perioperative antiemetic efficacy of midazolam 
with a placebo control. We hypothesized that midazolam would decrease vomiting after tonsillectomy in children.

\section{Methods}

With parental consent and Hospital Ethics Committee approval we studied 215 ASA physical status I or II children aged 1.5-14 yr undergoing tonsillectomy or adenotonsillectomy. Subjects were excluded if they had an allergy to a study drug or a non-study anaesthetic was deemed more appropriate. Subjects did not receive a premedicant.

After the placement of standard monitors, patients were sedated with $\mathrm{N}_{2} \mathrm{O}$, and anaesthesia was induced either by inhalation with halothane or with thiopentone $6 \mathrm{mg} \cdot \mathrm{kg}^{-1} i v$. After induction of anaesthesia, subjects were administered vecuronium $80 \mu \mathrm{g} \cdot \mathrm{kg}^{-1}$, fentanyl 1.5 $\mu \mathrm{g} \cdot \mathrm{kg}^{-1}$, and a study drug (midazolam $75 \mu \mathrm{g} \cdot \mathrm{kg}^{-1}$ or placebo) in a random, blocked, double-blind fashion. Anaesthesia was maintained with $70 \% \quad \mathrm{~N}_{2} \mathrm{O}$ and $0.75-1.5 \%$ halothane and titrated to maintain $\mathrm{HR}$ and SBP within normal limits. Upon completion of surgery, neuromuscular blockade was reversed with atropine 20 $\mu \mathrm{g} \cdot \mathrm{kg}^{-1}$ and neostigmine $60 \mu \mathrm{g} \cdot \mathrm{kg}^{-1}$. The tracheas were extubated after spontaneous ventilation had resumed and before the return of airway reflexes.

After the operation, patients received fentanyl 0.5 $\mu \mathrm{g} \cdot \mathrm{kg}^{-1} i v \mathrm{q} 5 \mathrm{~min}$ in the post-anaesthetic recovery room (PAR) if the modified CHEOPS pain score was $>6 .{ }^{12}$ In the Day Care Surgical Unit (DCSU), acetaminophen elixir $10 \mu \mathrm{g} \cdot \mathrm{kg}^{-1}$ and/or codeine $1 \mathrm{mg} \cdot \mathrm{kg}^{-1}, p o, p r$, or $i m$, was administered prn for pain. Excessive vomiting in the PAR or DCSU, that is vomiting >twice was treated with dimenhydrinate $1 \mathrm{mg} \cdot \mathrm{kg}^{-1} \dot{w}$. The length of stay in hospital after the operation was recorded. (The minimum stay after tonsillectomy in our institution at the time of this study was $240 \mathrm{~min}$.) Parents were contacted the day after surgery to ascertain the incidence of vomiting and other adverse events.

Data were compared with paired and unpaired $t$ tests, Mann-Whitney-U test, Chi-square analysis or Fisher Exact test, where appropriate. Acceptable alpha error was 0.05 . For sample size calculation the accepted beta error was 0.2 , the predicted incidence of vomiting in the placebo group and midazolam-treated group was $65 \%$ and $45 \%$, respectively.

\section{Results}

The groups were similar with respect to age, weight, sex, mode of induction, duration of anaesthesia, surgical procedure, opioid administration and length of stay in the PAR and the Day Care Surgical Unit (Tables I and II).
TABLE I Demographic data

\begin{tabular}{lllll}
\hline Group & $n$ & $\begin{array}{l}\text { Age } \\
(y r)\end{array}$ & $\begin{array}{l}\text { Weight } \\
(\mathrm{kg})\end{array}$ & Sex \\
\hline Placebo & 107 & $6.8 \pm 3.2$ & $27+15$ & $46 \%$ Male \\
Midazolam & 108 & $6.8 \pm 3.3$ & $25 \pm 13$ & $47 \%$ Male \\
\hline
\end{tabular}

mean $\pm \mathrm{SD}$.

TABLE II Anaesthesia and recovery times

\begin{tabular}{lll}
\hline Group & $\begin{array}{l}\text { Anaesthesia time } \\
\text { (min) }\end{array}$ & $\begin{array}{l}\text { In-hospital } \\
\text { postoperative time (min) }\end{array}$ \\
\hline Placebo & $32 \pm 9$ & $323 \pm 49$ \\
Midazolam & $33 \pm 12$ & $314 \pm 47$ \\
\hline
\end{tabular}

mean $\pm S D$.

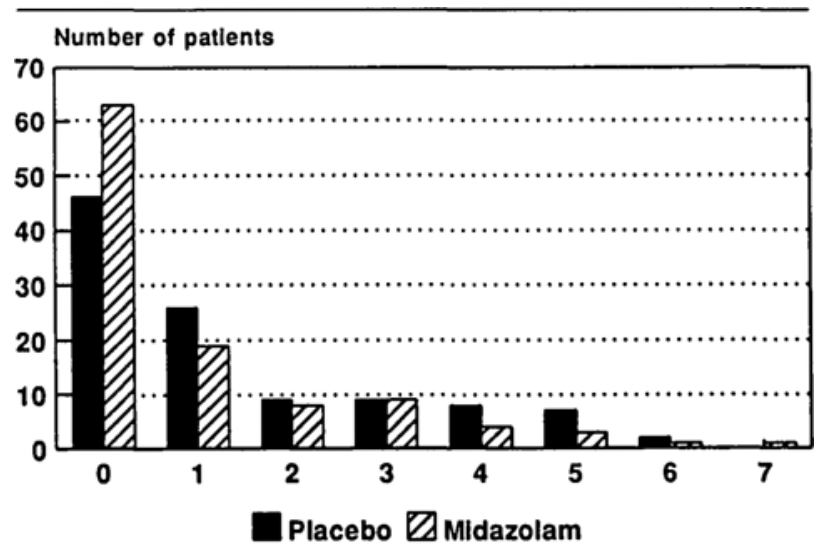

$\cdot P=0.028$, Mann-Whitnoy-U test, Placebo va Midazolam

FIGURE Number of episodes of emesis.

The 108 midazolam-treated children had a lower incidence ( $42 \%$ vs $57 \%$ ) of vomiting than the placebo group, $P<0.02$, Chi-square analysis. The number of times a patient vomited was greater in the placebo group (Figure). The incidence of unscheduled admissions to hospital due to vomiting was higher in the placebo group than the midazolam-treated group, $9 \%$ vs $2 \%, P<0.05$, Fisher exact test. No patient required readmission to hospital after discharge for vomiting or bleeding.

\section{Discussion}

Midazolam administered intravenously to children intraoperatively reduces vomiting after tonsil surgery. The mechanism of action of midazolam is unknown. Postulated mechanisms include glycinemimetic inhibitory effects, enhancement of inhibitory effects of gamma amino butyric acid (GABA), enhanced adenosinergic effects and inhibition of dopamine release. ${ }^{13,14}$ It has been proposed that benzodiazepines augment adenosine-mediated inhi- 
bition of dopamine in the chemoreceptor trigger zone which results in an antiemetic effect. ${ }^{13}$ In addition, Florio ${ }^{13}$ hypothesized that midazolam would act synergistically with antidopaminergic drugs. A more precise determination of the mechanism of action needs to be ascertained, but our clinical experience is consistent with current theories of the antidopaminergic and thus antiemetic activity of midazolam.

Antiemetic dose-response curves for midazolam are not currently available. In a previous investigation, we found midazolam $50 \mu \mathrm{g} \cdot \mathrm{kg}^{-1}$ to be as effective as the same dose of droperidol among patients undergoing strabismus repair. Thus, we conclude that midazolam 50-75 $\mu \mathrm{g} \cdot \mathrm{kg}^{-1}$ is an effective prophylactic antiemetic. This concurs with animal studies which demonstrate antidopaminergic activity at clinical levels of midazolam. ${ }^{14}$ It is unknown whether smaller doses are as effective and whether larger doses would be more effective.

The incidence of vomiting in this study was similar to those observed in other investigations. ${ }^{4,7,15,16}$ Midazolam was associated with a lower incidence of vomiting and a decreased incidence of unexpected admissions. The $42 \%$ incidence of vomiting in the midazolam-treated group was, in our opinion, unacceptably high. Further investigations need to be done to find a superior antiemetic or superior combination of drugs.

The patients in this investigation underwent either tonsillectomy ( $\mathrm{T}$ ) or adenotonsillectomy (T\&A). In theory, the T\&A patients may be at increased risk of bleeding and thus vomiting. However, in the past we have observed similar incidences of vomiting when comparing $T$ vs T\&A. ${ }^{4}$

We recognize that if the incidence of vomiting after discharge is recorded by the parents, there is a potential for underrecording. However, since the parents were unaware to which group their child belonged, we would expect any reporting bias to be equally distributed to both groups.

Although postoperative vomiting is an age-related phenomenon, because the groups studied were quite similar in age, any age effect would be equal for both groups.

In conclusion, the efficacy of prophylactic antiemetic treatment with midazolam before paediatric tonsillectomy was studied. Midazolam decreased vomiting and this contributed to a decreased incidence of unscheduled admissions to hospital.

\section{References}

1 Cohen MM, Cameron CC, Duncan PG. Pediatric anesthesia morbidity and mortality in the perioperative period. Anesth Analg 1990; 70: 160-7.

2 Pandit U, Pryn S, Randel G, Levy L, Lewis I. Nitrous oxide does not increase postoperative nausea/vomiting in pediatric outpatients undergoing tonsillectomyadenoidectomy. Anesthesiology 1990; 73: A1245.

3 Splinter $W M$, Noel L, Roberts D, Rhine E, Bonn G, Clarke $W$. Antiemetic prophylaxis for strabismus surgery. Can J Ophthalmol 1994; 29: 224-6.

4 Splinter WM, Rhine EJ, MacNeill HB, et al. The effect of general anaesthesia on post-tonsillectomy vomiting. Can J Anaesth 1990; 37: S96.

5 Rowley MP, Brown TCK. Postoperative vomiting in children. Anaesth Intensive Care 1982; 10: 309-13.

6 Clarke RSJ. Nausea and vomiting. Br J Anaesth 1984; 56: 19-27.

7 Grunwald ZVI, Schreiner MS, Parness J, Potsic WP, Templeton $J J$. Droperidol decreases the incidence and the severity of vomiting after tonsillectomy and adenoidectomy in children. Paediatric Anaesthesia 1994; 4: 163-7.

8 Olynyk JK, Cullen SR, Leahy MF. Midazolam: an effective antiemetic agent for cytotoxic chemotherapy (Letter). Med J Aust 1989; 150: 466.

9 Robins HI, Ershler WB, De Jongh L, et al. Antiemetic effect of intravenous diazepam in patients receiving cisdiamminedichloroplatinum II: a pilot study. Med Pediatr Oncol 1979; 7: 247-9.

10 Kearsley $J H$, Williams AM, Fiurmara $A-M$. Antiemetic superiority of lorazepam over oxazepam and methylprednisolone as premedicants for patients receiving cisplatincontaining chemotherapy. Cancer 1989; 64: 1595-9.

11 Khalil SN, Berry JM, Howard G, et al. The antiemetic effect of lorazepam after outpatient strabismus surgery in children. Anesthesiology 1992; 77: 915-9.

12 Splinter $W M$, Semelhago $L$, Chou $S$. The reliability and validity of a modified CHEOPS pain score. Anesth Analg 1994; 78 : $\$ 413$.

13 Di Florio T. The use of midazolam for persistent postoperative nausea and vomiting. Anaesth Intensive Care 1992; 20: 383-6.

14 Takada K, Murai T, Kanayama T, Koshikawa N. Effects of midazolam and flunitrazepam on the release of dopamine from rat striatum measured by in vivo microdialysis. Br J Anaesth 1993; 70: 181-5.

15 Litman RS, Wu CL, Catanzaro FA. Ondansetron decreases emesis after tonsillectomy in children. Anesth Analg 1994; 78: 478-81.

16 Ferrari $L R$, Donlon JV. Metoclopramide reduces the incidence of vomiting after tonsillectomy in children. Anesth Analg 1992; 75: 351-4. 